\title{
A prospective Comparative Clinical Study on Bladder Urine, Pelvic Urine and Renal Stone Culture \& Sensitivity in Predicting Urosepsis Following Percutaneous Nephrolithotomy
}

\author{
V. Vijay Kumar Reddy ${ }^{\circledR}$, Vijaya Bhaskar Reddy, G ${ }^{\circledR}$ \\ Assistant Professor, Department of Urology, Sapthagiri Institute of Medical Sciences and Research Center, Bangalore, Karnataka, India.
}

\section{Abstract}

Background: Urosepsis means a severe infection of urinary tract (UTI) and/or male genital tract (prostate) with features consistent with systemic inflammatory response syndrome. UTI may occur among all the age groups and produce a broad range of clinical syndromes ranging from asymptomatic bacteriuria to acute pyelonephritis with gram negative sepsis to septic shock. It is estimated that the mortality rate due to urosepsis ranges from 30 to 40 p.c respectively. Urosepsis may also cause multiple organ dysfunction, hypoperfusion or hypotension. Urosepsis due to percutaneous nephrolithotomy may be catastrophic despite prophylactic antibiotic coverage and negative midstream urine culture and sensitivity testing $(\mathrm{C} \& \mathrm{~S})$ and bacteria in the stone can be responsible for systemic infection. The aim of the study is to compare bladder urine (culture \& sensitivity) and collecting system urine and stone (culture and sensitivity) in predicting urosepsis following percutaneous nephrolithotomy. Subjects and Methods: A hospital-based, analytical prospective clinical study was conducted among thirty cases who were present during the study period and had undergone percutaneous nephrolithotomy (PCNL). Cases were included irrespective of gender with renal calculi in whom percutaneous nephrolithotomy was about to be done at Narayana Medical College \& Hospital, Chintareddypalem, Nellore, Andhra Pradesh during $1^{\text {st }}$ February 2014 to $31^{\text {st }}$ January 2015. Data collected was divided into three main groups Midstream urine (C\&S); Pelvic urine $(C \& S)$; and Stone (C\&S) respectively. Data obtained was entered in Microsoft Excel-2013 and analyzed in SPSS version-22 trial. Appropriate statistical tests were applied and p-value less than 0.05 was considered as significant. Results: Bladder urine (C\&S) was positive in $3 / 30(10.00$ $\%)$ patients, Pelvic urine (C\&S) in 5/30 (16.66\%) patients and Stone (C\&S) in 8/30 (26.66 \%) patients. Most of the infected specimens grew Escherichia coli followed by pseudomonas, klebsiella, enterococcus. Systemic Inflammatory Response Syndrome (SIRS) was reported among 26.7 p.c (8) of the patients. In one patient (3.33\%) septic shock developed but no deaths were reported. Conclusion: Stone (C\&S) and Pelvic urine $(\mathrm{C} \& \mathrm{~S})$ are better predictors of urosepsis than Bladder urine $(\mathrm{C} \& \mathrm{~S})$.

Keywords: Percutaneous nephrolithotomy, Urosepsis

Corresponding Author: Vijaya Bhaskar Reddy. G, Assistant Professor, Department of Urology, Sapthagiri Institute of Medical Sciences and Research Center, Bangalore, Karnataka, India.

E-mail: basjay1001@gmail.com

Received: 17 January 2020

Revised: 21 February 2020

Accepted: 06 March 2020

Published: 26 May 2020

\section{Introduction}

Urosepsis means a severe infection of urinary tract (UTI) and/or male genital tract (prostate) with features consistent with systemic inflammatory response syndrome. ${ }^{[1]}$ UTI may occur among all the age groups and produce a broad range of clinical syndromes ranging from asymptomatic bacteriuria to acute pyelonephritis with gram negative sepsis to septic shock. ${ }^{[2]}$ Urosepsis may also cause multiple organ dysfunction, hypoperfusion or hypotension. ${ }^{[2]} \mathrm{A}$ severe sepsis condition may be usually associated with abdominal and pulmonary infections with UTIs which account for about 5 p.c of the cases. ${ }^{[3]}$ About 40 p.c of the urinary tract infections were due to nosocomial infections. ${ }^{[4]}$ About 25 p.c of the sepsis cases originate from urogenital

system. ${ }^{[5]} \mathrm{A}$ percutaneous nephrolithotomy is a minimally invasive surgical procedure performed to treat patients with a large and complex renal calculi. ${ }^{[6]}$

Urosepsis is a complication which occur after a percutaneous nephrolithotomy among 0.3 to 2.5 p.c cases. ${ }^{[7]}$ Staghorn urinary calculi may harbor bacteria. The fragmented stones, despite sterile urine, may release bacterial endotoxins and viable bacteria that place the patient at risk for septic complication. ${ }^{[8,9]}$ Itise stimated that the mortality rate due to urosepsis ranges from 30 to 40 p.c respectively. ${ }^{[10]}$ The most 
common pathogens causing UTIs (and in turn urosepsis) are Escherichia coli (50\%), Proteus (15\%), Enterobacter (15\%), Klebsiella (15\%), Pseudomonas aeruginosa (5\%) and grampositive bacteria $(15 \%)$ respectively. ${ }^{[11]}$

The clinical presentation of urosepsis includes fever, tachycardia, tachypnea, respiratory alkalosis which were earlier considered to be mandatory for the diagnosis of sepsis, are now considered to be the alerting symptoms. ${ }^{[2]}$ Systemic inflammatory response syndrome includes body temperature $\left(\geq 38^{\circ} \mathrm{C}\right)$ / $\left(\leq 36^{\circ} \mathrm{C}\right)$; tachycardia $(\geq 90$ beats/min); tachypnea $(\geq 20$ breaths/min); respiratory alkalosis $\left(\mathrm{PaCO}_{2} \leq 32 \mathrm{~mm} \mathrm{Hg}\right)$; leucocytes $(\geq 12000$ or $\leq 4000$ cells $/ \mu \mathrm{L}) .{ }^{[2]}$ Risk factors for urosepsis include surgical patients, weakened immune system, kidney transplant recipients, chronic illness, recent diagnosis of UTI, H/o recurrent UTI, H/o urosepsis, urinary tract disorders, elderly, diabetic, frequent catheterization, recent catheterization, inability to fully empty the bladder and indwelling (long-term) catheter. ${ }^{[12]}$ Urosepsis due to percutaneous nephrolithotomy may be catastrophic despite prophylactic antibiotic coverage and negative midstream urine culture and sensitivity testing (C\&S) and bacteria in the stone can be responsible for systemic infection.

\section{Aim \& Objectives}

- To compare bladder urine (culture \& sensitivity) and collecting system urine and stone (culture and sensitivity) in predicting urosepsis following percutaneous nephrolithotomy.

\section{Subjects and Methods}

A hospital-based, analytical prospective clinical study was conducted among thirtycases who were present during the study period and had undergone percutaneous nephrolithotomy (PCNL). Cases were included irrespective of gender with renal calculi in whom percutaneous nephrolithotomy was about to be done. Patients with a stent, nephrostomy tube or indwelling catheter, concomitant bladder stone, contralateral ureteral stone, previous manipulation or procedure and immuno compromised state were excluded from the study. The study was conducted for a period of 1 year from $1^{\text {st }}$ February 2014 to $31^{\text {st }}$ January 2015 at Narayana Medical College \& Hospital, Chintareddypalem, Nellore, Andhra Pradesh. A prior permission from the institutional ethics committee and written consent from the patients and their family members were obtained. Patient was placed in lithotomy position; betadine preparation of perineum and cystoscopy was done. Through a ureteric orifice of 0.0035 inch terumo guidewire was introduced into pelvicalyceal system. A $5 \mathrm{fr}$ ureteric catheter was guided into the pelvicalyceal system over the guidewire and the position was confirmed by fluoroscopic guidance. Later the patient was turned to prone position, after an aseptic preparation percutaneous puncture was done by chiba needle and its position was confirmed by aspiration of urine, which was sent for culture. Nephoscopy was performed and stone was visualized \& fragmented with a pneumatic lithotripter. Stone fragments were retrieved and collected into a sterile bottle.Nemoy and Stamey method was used for stone culture and sensitivity.Patients were monitored closely during post-operative period for any signs of sepsis. Data collected was divided into three main groups Midstream urine $(\mathrm{C} \& S)$; Pelvic urine $(\mathrm{C} \& S)$; and Stone $(\mathrm{C} \& S)$ respectively.Dataobtained was entered in Microsoft Excel-2013 and analyzed in SPSS version-22 trial. Appropriate statistical tests were applied and p-value less than 0.05 was considered as significant.

\section{Results}

In the present study 30 patients were included based on the selection criteria. Table-1 reports that majority 73.3 p.c (22) were males followed by 26.7 p.c (8) were females respectively. Majority of the patients were above 30 years of age, two were pediatric patients. Figure-1 reports that maximum number of isolates were from stones followed by pelvic urine and least from bladder urine. Bladder urine $(\mathrm{C} \& S)$ was positive in $3 / 30(10.00 \%)$ patients,Pelvic urine $(\mathrm{C} \& S)$ in $5 / 30(16.66$ $\%)$ patients and Stone (C\&S) in 8/30 (26.66 \%) patients.Most of the infected specimens grew Escherichia coli followed by pseudomonas, klebsiella, enterococcus.Systemic Inflammatory Response Syndrome (SIRS) was reported among26.7 p.c (8) of the patients. In one patient (3.33\%) septic shock developed but no deaths were reported. Table-2 \& Figure2 reports the Systemic Inflammatory Response Syndrome (SIRS) among the patients. Correlation between the various specimens and SIRS revealed that infected stone (C\&S) and pelvic urine (C\&S) carried a 4-fold risk of urosepsis.A total of 20 patients had radiological evidence of a dilated pelvicalyceal system (hydronephrosisor caliectasis) and the incidence of positive pelvic urine $(C \& S)$ in this subgroup was significantly higher than in those without obvious dilatation ( $p$-value $=0.046$ ). Despite this, hydronephrosis did not correlate with SIRS ( $\mathrm{p}$-value $=0.529$ ). Operative time had a positive linear relationship with stone bulk $(\mathrm{r}=0.723$, $\mathrm{p}$-value $=0.01)$. Infected stones appeared to be larger than non-infected ones. About 7stonesgreater than $30 \mathrm{~mm}$ size were culture positive compared with 1 stone that was $30 \mathrm{~mm}$ or less ( $\mathrm{p}$-value $=0.039$ ), which may have reflected their etiology. There was a similarly poor correlation between SIRS and age ( $\mathrm{p}$-value=0.66), gender ( $\mathrm{p}$-value $=0.44)$, difficult access $(\mathrm{p}$-value $=0.903)$ and residual stones postoperatively ( $\mathrm{p}$-value $=0.857)$. Table- 3 reports distribution of patients based on hydronephrosis \& SIRS. Table-4 reports prediction of SIRS using different specimens. 
Table 1: Showing Demographic Factors

\begin{tabular}{|llll|}
\hline Demographic Factors & & Number Of Patients & \% Of Patients \\
\hline Gender & Male & 22 & 73.3 \\
\hline Age (Years) & Female & 8 & 26.7 \\
& $<10$ & 1 & 3.3 \\
\hline $11-20$ & 4 & 13.3 \\
\hline $21-30$ & 7 & 23.3 \\
\hline & $31-40$ & 10 & 33.3 \\
\hline & $41-50$ & 5 & 16.8 \\
\hline
\end{tabular}

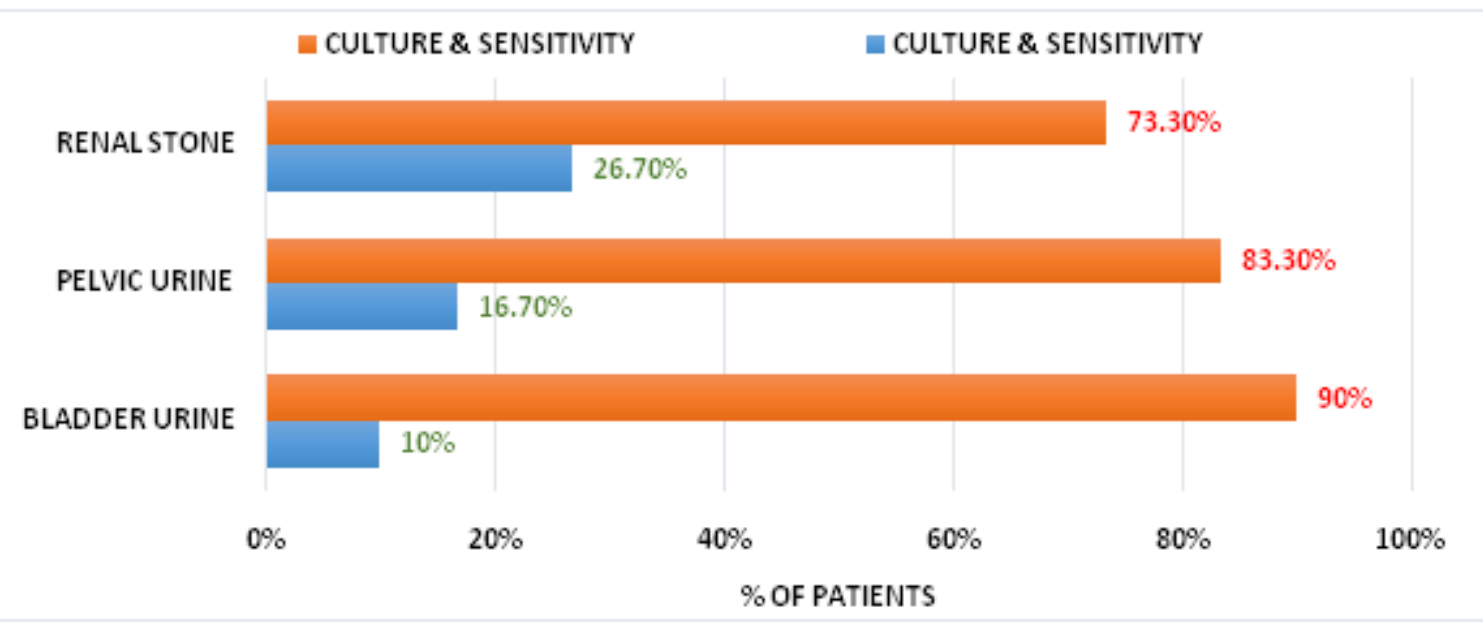

Figure 1: Showing Comparison of culture Results

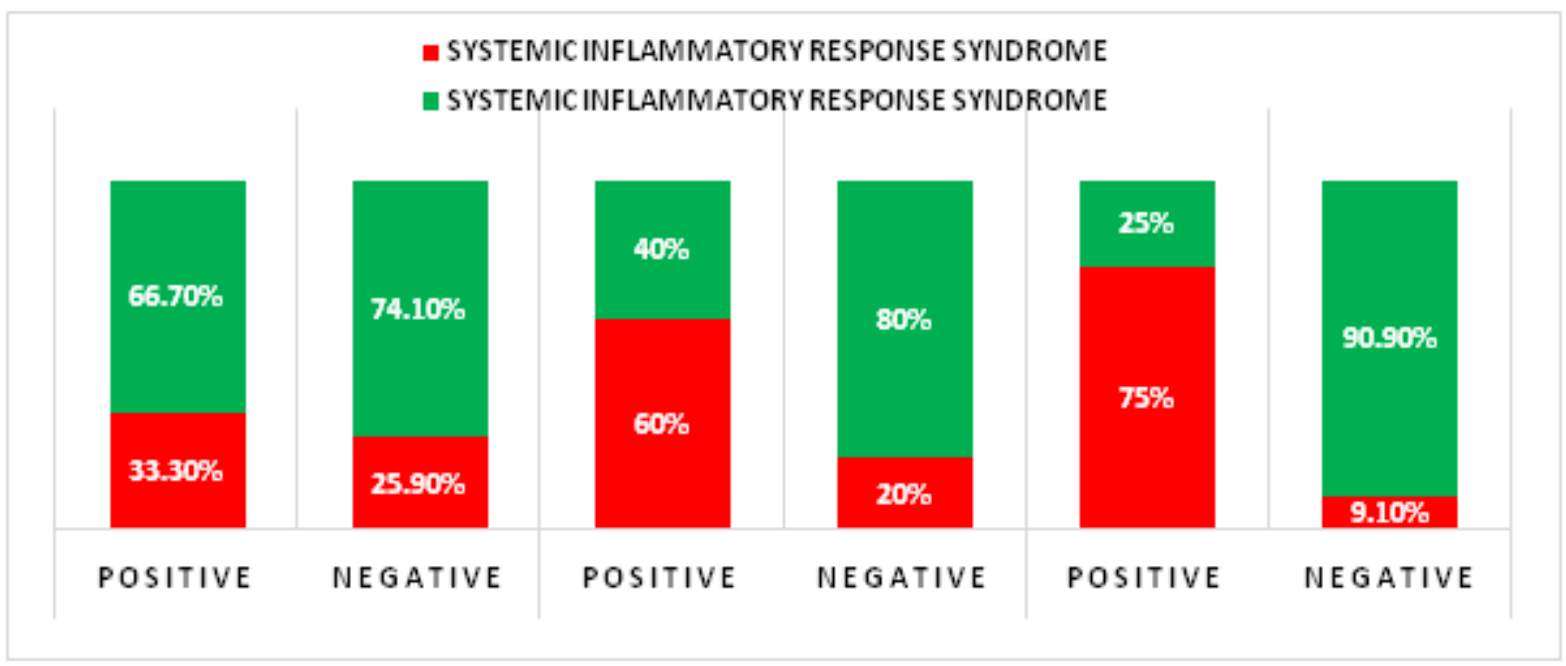

Figure 2: Showing Systemic Inflammatory Response Syndrome 


\begin{tabular}{llll|}
\hline \multicolumn{3}{|l}{ Table 2: Showing Systemic Inflammatory Response Syndrome (SIRS) in Various Samples Tested } \\
\hline Sample & \multicolumn{3}{c|}{ Systemic Inflammatory Response Syndrome } \\
& & Present (\%) & Absent (\%) \\
Bladder Urine & Positive & $1(33.3)$ & $2(66.7)$ \\
& Negative & $7(25.9)$ & $20(74.1)$ \\
Pelvic Urine & Positive & $3(60)$ & $2(40)$ \\
& Negative & $5(20)$ & $20(80)$ \\
Renal Stone & Positive & $6(75)$ & $2(25)$ \\
& Negative & $2(9.1)$ & $20(90.9)$ \\
\hline
\end{tabular}

Table 3: Showing Distribution of Patients Based on Hydronephrosis \& SIRS

\begin{tabular}{lllll}
\hline SIRS & Dilated Pcs & \multicolumn{3}{l}{ Normal Pcs } \\
& Pelvic Urine (C/S) & \multicolumn{3}{l}{ Pelvic Urine (C/S) } \\
& Present & Negative & Present & Negative \\
Present & 2 & 4 & 1 & 1 \\
\hline Absent & 2 & 12 & 0 & 8 \\
\hline
\end{tabular}

\section{Table 4: Showing Prediction of SIRS Using Different Specimens}

\begin{tabular}{llll}
\hline & Bladder Urine $\mathbf{C} / \mathbf{S}$ & Pelvic Urine $\mathbf{C} / \mathbf{S}$ & Stone $\mathbf{C} / \mathbf{S}$ \\
\hline Sensitivity & 12.5 & 37.5 & 87.5 \\
Specificity & 90.9 & 90.9 & 95.45 \\
PPV & 0.33 & 0.6 & 0.87 \\
NPV & 0.74 & 0.8 & 0.95 \\
RR $(95 \%$ CI $)$ & $1.37(0.14-13.17)$ & $4.12(0.83-20.34)$ & $19.5(2.7-132.9)$ \\
\hline
\end{tabular}

\section{Discussion}

In our study Stone (C\&S) was positive in 26.7 p.c and MidStream urine (MSU) (C\&S) was positive in only one of them (12.5 p.c). Fowler et al who reported a stone positive rate of 77.3 p.c and found that urine (C\&S) was simultaneously positive in only 12.5 p.c of patients with infected stones. ${ }^{[13]}$ Similarly Bratell et al ${ }^{[14]}$ and Mc Cartneyet al ${ }^{[15]}$ confirmed a poor correlation between infection in the stone and in bladder urine specimens.

Cadeddu et $\mathrm{al}^{[16]}$ study reviewed 66 records of patients with PCNL who had sterile urine preoperatively. Of the 28.8 p.c of patients in whom fever greater than $38^{\circ} \mathrm{C}$ developed none had positive blood or postoperative urine $(\mathrm{C} \& \mathrm{~S})$. In our study also none of the patients with SIRS $(26.7 \%)$ had positive blood $(\mathrm{C} / \mathrm{S})$. Caddedu et al ${ }^{[16]}$ reported no correlation between fever and stone composition, although stone culture was not performed. Fever alone cannot be used as an indicator of systemic infection, as noted in the study of Rao et al ${ }^{[17]}$, in which 74 p.c of patients with PCNL had fever postoperatively but only 41p.c had endotoxemia.

\section{Conclusion}

Stone $(\mathrm{C} \& \mathrm{~S})$ and Pelvic urine $(\mathrm{C} \& \mathrm{~S})$ are better predictors of urosepsis than Bladder urine $(\mathrm{C} \& \mathrm{~S})$.

\section{References}

1. Kalra OP, Raizada A. Management issues in urinary tract infections. J Gen Med. 2006;18:16-22.

2. Kalra OP, Raizada A. Approach to a patient with urosepsis. J Global Inf Dis. 2009;1(1):57-61.

3. Hotchkiss RS, Karl IE. The Pathophysiology and Treatment of Sepsis. New England J Med. 2003;348(2):138-150. Available from: https://dx.doi.org/10.1056/nejmra021333. doi:10.1056/nejmra021333.

4. Gastmeier P, Kampf G, Wischnewski N, Hauer T, Schulgen $\mathrm{G}$, Schumacher M, et al. Prevalence of nosocomial infections in representative German hospitals. J Hospital Inf. 1998;38(1):37-49. Available from: https://dx.doi.org/10.1016/ s0195-6701(98)90173-6. doi:10.1016/s0195-6701(98)901736.

5. Thornton HV, Hammond A, Hay AD. Urosepsis: a growing and preventable problem? $\mathrm{Br} \mathrm{J}$ Gen Practice. 
2018;68(675):493-494. Available from: https://dx.doi.org/10. 3399/bjgp18x699317. doi:10.3399/bjgp18x699317.

6. Wickham JEA, Miller RA, Kellet MJ, Payne SR. Percutaneous Nephrolithotomy: One Stage or Two? Br J Urol. 1984;56(6):582-585. Available from: https://dx.doi. org/10.1111/j.1464-410x.1984.tb06121.x. doi:10.1111/j.1464410x.1984.tb06121.x.

7. Charton M, Vallancien G, Veillon B, Brisset JM. Urinary Tract Infection in Percutaneous Surgery for Renal Calculi. J Urol. 1986;135(1):15-17. Available from: https://dx. doi.org/10.1016/s0022-5347(17)45500-5. doi:10.1016/s00225347(17)45500-5.

8. Paterson RF, Kuo RL, Lingeman JE. Staghorn calculus endotoxin expression in sepsis. Urol. 2003;62(1):197-197. Available from: https://dx.doi.org/10.1016/s0090-4295(02)02132-5. doi:10.1016/s0090-4295(02)02132-5.

9. Scherz HC, Parsons CL. Prophylactic antibiotics in urology. Urol Clin North Am. 1987;14(2):265-271.

10. Areda MA, Bailey CR, O'Mara D, Weiss CR. Transplant uretero-inguinal hernia resulting in urosepsis. Radiol Case Rep. 2018;14(1):14-17. Available from: https://pubmed.ncbi.nlm. nih.gov/30305858/. doi:10.1016/j.radcr.2018.09.002.

11. Vikrant S, Gupta D, Singh M. Epidemiology and outcome of acute kidney injury from a tertiary care hospital in India. Saudi Journal of Kidney Diseases and Transplantation. 2018;29(4):956-956. Available from: https://dx.doi.org/10. 4103/1319-2442.239633. doi:10.4103/1319-2442.239633.

12. Kalra OP, Raizada A. Approach to a patient with urosepsis. J Glob Infect Dis. 2009;1(1):57-63.

13. Fowler JE. Bacteriology of Branched Renal Calculi and Accompanying Urinary Tract Infection. J Urol. 1984;131(2):213-215. Available from: https://dx.doi. org/10.1016/s0022-5347(17)50311-0. doi:10.1016/s00225347(17)50311-0.
14. Bratell S, Brorson JE, Grenabo L, Hedelin H, Pettersson S. The Bacteriology of Operated Renal Stones. Eur Urol. 1990;17(1):58-61. Available from: https://dx.doi.org/10.1159/ 000464001. doi:10.1159/000464001.

15. McCartney AC, Clark J, Lewi HJE. Bacteriological study of renal calculi. Eur J Clin Microbiol. 1985;4(6):553555. Available from: https://dx.doi.org/10.1007/bf02013393. doi:10.1007/bf02013393.

16. Cadeddu JA, Chen R, Bishoff J, Micali S, Kumar A, Moore RG, et al. Clinical Significance of Fever After Percutaneous Nephrolithotomy. Urol. 1998;52(1):48-50. Available from: https://dx.doi.org/10.1016/s0090-4295(98)00146-0. doi:10.1016/s0090-4295(98)00146-0.

17. Rao PN, Dube DA, Weightman NC, Oppenheim BA, Morris J. Prediction of Septicemia Following Endourological Manipulation for Stones in the Upper Urinary Tract. J Urol. 1991;146(4):955-960. Available from: https://dx. doi.org/10.1016/s0022-5347(17)37974-0. doi:10.1016/s00225347(17)37974-0.

Copyright: (C) the author(s), 2020. It is an open-access article distributed under the terms of the Creative Commons Attribution License (CC BY 4.0), which permits authors to retain ownership of the copyright for their content, and allow anyone to download, reuse, reprint, modify, distribute and/or copy the content as long as the original authors and source are cited.

How to cite this article: Reddy VVK, VBRG. A prospective Comparative Clinical Study on Bladder Urine, Pelvic Urine and Renal Stone Culture \& Sensitivity in Predicting Urosepsis Following Percutaneous Nephrolithotomy. Acad. J Surg. 2020; 3(1):75-79.

DOI: dx.doi.org/10.47008/ajs/2020.3.1.16

Source of Support: Nil, Conflict of Interest: None declared. 